\title{
CAFFEINE, MAXIMAL POWER OUTPUT AND FATIGUE
}

\author{
J. H. WILLIAMS, J. F. SIGNORILE, W. S. BARNES and T. W. HENRICH
}

Neuromuscular Research Unit, Human Performance Laboratories, Department of Health and Physical Education, Texas A\&M University, USA

\section{ABSTRACT}

The purpose of this investigation was to determine the effects of caffeine ingestion on maximal power output and fatigue during short term, high intensity exercise. Nine adult males performed $15 \mathrm{~s}$ maximal exercise bouts 60 min after ingestion of caffeine (7 mg.kg-1) or placebo. Exercise bouts were carried out on a modified cycle ergometer which allowed power output to be computed for each one-half pedal stroke via microcomputer. Peak power output under caffeine conditions was not significantly different from that obtained following placebo ingestion. Similarly, time to peak power, total work, power fatigue index and power fatigue rate did not differ significantly between caffeine and placebo conditions. These results suggest that caffeine ingestion does not increase one's maximal ability to generate power. Further, caffeine does not alter the rate or magnitude of fatigue during high intensity, dynamic exercise.

Key words: Caffeine, Maximal power output, Fatigue

\section{INTRODUCTION}

It is considered by many athletes and in much of the popular literature that caffeine (1,3,7-trimethylxanthine) improves sports performance and is thus an ergogenic aid. However, a review of the scientific literature does not provide clear support of this notion. Much of the belief that caffeine aids performance is based on its direct actions on isolated tissue(s). Included among caffeine's actions are stimulation of the central nervous system and of cardiac muscle, relaxation of smooth muscle and mobilisation of free fatty acids (for review see Van Handle, 1983). There exists a large body of evidence suggesting that caffeine also has marked effects on skeletal muscle function. It has been demonstrated that caffeine in concentrations up to $2.5 \mathrm{mmol} . \mathrm{I}^{-1}$ potentiates isometric twitches in directly stimulated isolated muscle and indirectly stimulated nervemuscle preparations (Connett et al, 1983; Varagic and Zugic, 1971; Yamaguchi, 1975). In higher concentrations

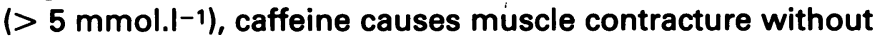
significant membrane depolarisation (Yamaguchi, 1975). These effects have also been shown to occur in rested muscle and in muscle that has been fatigued by repetitive stimulation (Eberstein and Sandow, 1963; Maclntosh et al, 1981). Twitch potentiation and contractures appear to be related to increased calcium availability to the contractile mechanism resulting from enhancement of the "calciuminduced" calcium release mechanism of the sarcoplasmic reticulum (Endo, 1977). It has also been demonstrated that caffeine facilitates neuromuscular transmission and increases neuronal excitability by reducing the threshold of motor neurone firing and/or by reducing the adenosine inhibition of firing (Breckinridge et al, 1967; Daly et al, 1981; Varagic and Zugic, 1971; Waldek, 1973; Wilson, 1973). This could result in increased motor unit recruitment and altered patterns of substrate utilisation in the active muscle fibres (Van Handle, 1983).

It is tempting to speculate that during a brief, high intensity exercise bout, caffeine induced changes in neuromuscular function and metabolism might increase the maximal power generated and/or alter the rate of fatigue. To date, few data exist to describe caffeine's effect on

Address for correspondence:

J. H. Williams

Department of Health and Physical Education

Virginia Tech University

Blacksburg

Virginia 24061

USA performance during short term, dynamic exercise. Therefore, the purpose of this investigation was to determine the effects of caffeine ingestion on maximal power output and fatigue during short-term cycling exercise.

\section{METHODS}

Subjects were nine adult males (age $=26.3 \pm 2.0 \mathrm{y}$; weight $=75.2 \pm 2.3 \mathrm{~kg}$; height $=178.3 \pm 1.9 \mathrm{~cm})($ mean \pm SEM) who were known to have a low daily intake of caffeine (i.e. $<70$ per day). All were informed as to the nature of these experiments and gave informed consent prior to testing. Subjects were asked to abstain from caffeinated foods and beverages for one week prior to testing and to maintain that diet throughout the duration of the investigation.

A double-blind experimental procedure was followed with high intensity cycling exercise bouts being performed approximately $60 \mathrm{~min}$ after subjects ingested equal numbers of gelatin capsules containing caffeine ( $\left.7 \mathrm{mg} \cdot \mathrm{kg}^{-1}\right)$ or placebo. Trials were separated by a 48-hour recovery interval with the treatment order being counterbalanced. After a $60 \mathrm{~min}$ absorption period, a venous blood sample $(10 \mathrm{ml})$ was withdrawn for subsequent analysis of plasma caffeine concentration (Axelrod and Reichenthal, 1953; Routh et al, 1969).

All exercise bouts were performed on a modified Monark cycle ergometer which allowed power output to be computed for each one-half pedal stroke. The ergometer's flywheel resistance strap was attached to an electronic load cell (LeBow Model 3167), wrapped around the flywheel and over a pully so that calibrated weights could be attached. Two small magnets were affixed to the pedal sprocket and a magnetic reed switch was attached to the ergometer frame near the top of the pedal sprocket. A 5-volt power supply was connected to the switch so that pedalling resulted in the magnets passing over the switch and generating two square wave pulses per pedal revolution. Amplified (Daytronics Model 3270 Strain Gauge Conditioner) signals from the load cell and the closures of the switch were sampled $(512 \mathrm{~Hz})$, digitised and stored on disk for later analysis by microcomputer (Hewlett-Packard 9000 Series 300). Flywheel velocity was computed for each one-half pedal revolution or pulse-to-pulse interval by dividing the distance travelled by the flywheel $(3 \mathrm{~m})$ by the time duration between pulses. The applied resistive load was calculated as the difference between the load attached to the resistive strap and that registered by the load cell. Power output was then computed as the product of force and velocity.

Immediately prior to power testing, subjects were allowed a 5 minute warm-up at a pedal cadence of $60 \mathrm{rpm}$ 
(50 W). Following the warm-up, lead disks of mass $11.4 \mathrm{~kg}$ resulting in an applied load of 80.4-80.2 $\mathrm{N}$ were attached to the resistive strap. Subjects were then instructed to accelerate the ergometer from rest and to continue pedalling as fast as possible for 15 seconds. Data collection was triggered externally by the first pulse generated by the magnetic switch.

To describe the changes in power output during the test, each power value was plotted against the midpoint of its pulse-to-pulse interval. The power curves were then analysed for the highest power output achieved in one-half pedal stroke (peak power - PP, W), time to peak power (TTPP, s), the relative decline from peak power at the end of the $15 \mathrm{sec}$ test (power fatigue index - PFI, \%), the average rate of power decline from peak power (power fatigue rate - PFR, W.s ${ }^{-1}$ ) and the total amount of work accomplished during the $15 \mathrm{~s}$ test (total work - TW, W). Pilot studies have shown that for tests administered on separate days, the test-retest reliabilities of these parameters is between 0.93 and 0.97 .

The mechanical parameters of the power curve were analysed for treatment differences using analysis of variance for repeated measures. Significance was established at $P<0.05$.

\section{RESULTS AND DISCUSSION}

Blood plasma caffeine concentrations under placebo conditions ranged from $0.89 \mu \mathrm{g} \cdot \mathrm{ml}^{-1}$ to $1.22 \mu \mathrm{g} \cdot \mathrm{ml}^{-1}$ (1.06 \pm $\left.0.22 \mu \mathrm{g} . \mathrm{ml}^{-1}\right)$. Sixty minutes following caffeine ingestion, plasma levels ranged from $9.37 \mu \mathrm{g} \cdot \mathrm{ml}^{-1}$ to $13.11 \mu \mathrm{g} \cdot \mathrm{ml}^{-1}$ (10.56 $\pm 0.58 \mu \mathrm{g} \cdot \mathrm{ml}^{-1}$ ). The post-ingestion levels were significantly elevated compared with placebo conditions $(P<0.05)$.

Statistical analyses revealed that acute caffeine ingestion has no significant effect on PP, PFI or TW. Similar results were found for the time-dependent parameters TTPP and PFR. These data are summarised in Table I. Composite power curves for each treatment are presented in Fig. 1. The values presented are means \pm SEM of individual $1 \mathrm{~s}$ power averages and were not significantly different between treatments.

\section{TABLE I}

Comparison of peak power output (PP), time to peak power (TTPP), total work (TW), power fatigue index (PFI) and power fatigue rate (PFR) between placebo and caffeine conditions. Values are mean (SEM)

\begin{tabular}{lcc}
\hline Variable & Placebo & Caffeine \\
\hline PP (W) & $1002.48(23.45)$ & $1010.74(25.23)$ \\
TTPP (s) & $3.24(0.29)$ & $3.29(0.38)$ \\
TW (W) & $12.35(0.45)$ & $12.74(0.35)$ \\
PFI (\%) & $30.16(2.86)$ & $28.07(1.37)$ \\
PFR (W.s & $28.92(2.31)$ & $26.96(2.62)$ \\
\hline
\end{tabular}

It is possible that when using a mechanically braked ergometer, power output values might be influenced by the inertia of the flywheel. Lakomy (1986) has suggested that a considerable amount of unmeasured work is performed when accelerating the flywheel. However, we have calculated that, based on the mass moment of inertia of a solid disk and the flywheel velocities and loading conditions used in this study, the contribution of flywheel inertia to power output is small. Nonetheless, when our data is adjusted to account for work done during flywheel acceler-

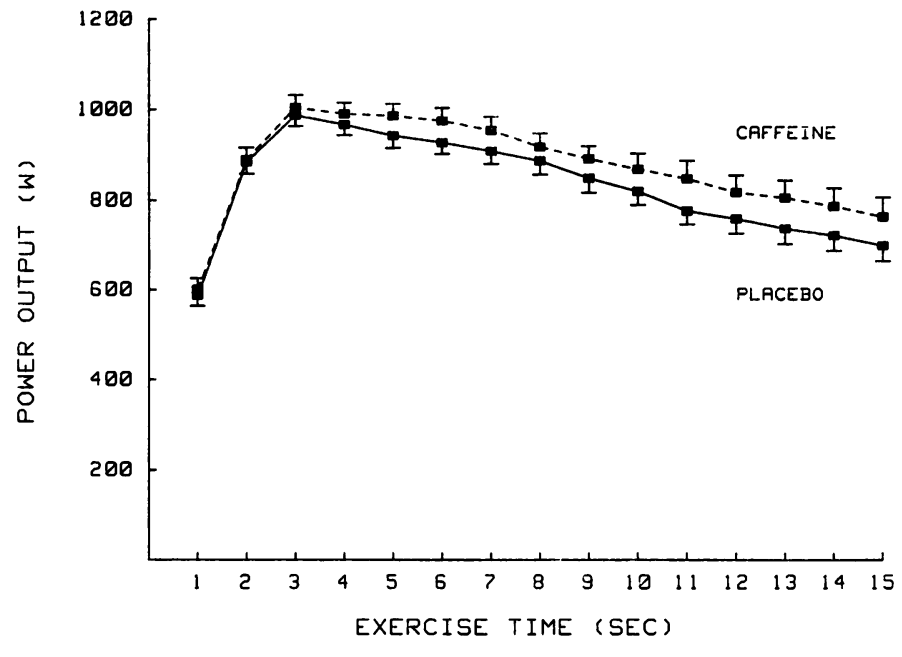

Fig. 1: Composite power curves under placebo (solid line) and caffeine (dashed line) conditions. Values are mean \pm SEM of individual 1 sec averages.

ation as proposed by Lakomy (1986), statistical analyses showed results similar to those obtained from the original data.

The results of this investigation clearly show that caffeine ingestion does not improve maximal power output or delay fatigue during high intensity, isotonic exercise. These data are in general agreement with previous reports of caffeine's effects on maximal voluntary contractions and endurance during isokinetic and isometric exercise. Bond and co-workers have recently shown that caffeine has no effect on peak torque, power and fatigue during isokinetic knee extension and flexion (Bond et al, 1986). Several reports have shown that maximal isokinetic handgrip contractions are not improved following caffeine ingestion (Blythe et al, 1960; Bugyi, 1980; Williams et al, 1987) and maximal holding time during submaximal contractions is not increased (Lopes et al, 1983; Williams et al, 1987). Thus it appears that caffeine has little if any effect on performance in activities which require maximal strength, maximal power and/or resistance to short term fatigue.

There appear to be several possible reasons for the lack of an effect of caffeine. Firstly, Connett et al (1983) have demonstrated that caffeine potentiates twitch tensions in isolated rat muscle at concentrations as low as $50 \mu \mathrm{m} . \mathrm{I}^{-1}$. Ingestion of $7 \mathrm{mg} \cdot \mathrm{kg}^{-1}$ of caffeine in the present study resulted in mean plasma concentrations near this level. Based on these pieces of evidence, it might be expected that acute ingestion would have some direct effect on muscle contractility and subsequent power production, in vivo. However, it should be noted that in humans, a large fraction of caffeine in the blood is bound to plasma proteins and is biologically inactive (Rall, 1980). Due to this, the effective caffeine concentration at the muscle may have been somewhat less than that determined via assay of blood, possibly too low to elicit and effect. Secondly, Fredholm (1985) has suggested that caffeine's primary actions in humans are mediated via adenosine antagonism, namely sympathetic stimulation and catacholamine release. It has further been suggested that blockade of adenosine receptors may increase neuronal activity and facilitate motor unit recruitment (Fernstrom and Fernstrom, 1984). However, Van Handle (1983) has noted that the sympathetic response to maximal work stress might be of such magnitude that it supercedes the caffeine-induced changes observed in vitro, in situ or resting in vivo investigations. Additionally, 
Williams et al (1987) have demonstrated that maximal motor unit activation, defined as the integral of the electromyogram during maximal contraction, was not significantly increased by caffeine ingestion. Thus it appears that caffeine ingestion resulted in plasma concentrations which were too low to elicit effects on performance and/or that any caffeine-induced effects were masked by the response to the exercise bout.

In summary, these results that acute caffeine ingestion does not appear to increase one's maximal ability to generate power during short-term cycling exercise. Further, caffeine does not alter the rate or magnitude of fatigue during high intensity, dynamic exercise.

\section{References}

Axelrod, J. and Reichenthal, J., 1953 "The fate of caffeine in man and a method for its elimination in biological materials". J.Pharm.Exper.Ther. 107: 519-523.

Blythe, C. S., Allen, E. M. and Lovingwood, B. W., 1960 "Effects of amphetamine (dexedrine) and caffeine on subjects exposed to heat and exercise stress". Res.Quart. 31: 553-559, 1960.

Bond, V., Gresham, K., McRea, J. and Tearney, R. J., 1986 "Caffeine ingestion and isokinetic strength". Brit.J.Sports Med. 20: 135-137.

Breckinridge, B. M., Burn, J. H. and Matshinsky, F. M., 1967 "Theophylline, epinephrine and neostigmine facilitation on neuromuscular transmission". Proc.Natl.Acad.Sci.(Wash.) 57: 1893-1897.

Bugyi, G. J., 1980 "The effects of moderate doses of caffeine on fatigue parameters of the forearm flexor muscles". Amer.Corr.Ther.J. 34: 49-53.

Connett, R. J., Ugol, L. M., Hammack, M. J. and Hays, E. T., 1983 "Twitch potentiation and caffeine contractures in isolated rat soleus muscle". Comp.Biochem.Physiol. 74C: 349-354.

Daly, M. J., Bruns, R. F. and Snyder, S. H., 1981 "Adenosine receptors in the central nervous system: Relationship to the central actions of methylxanthines". Life Sci. 28: 2083-2097.
Eberstein, A. and Sandow, A., 1963 "Fatigue mechanisms in muscle fibers". In: Effects of Use and Disuse of Neuromuscular Functions, Edited by E. Gutmann, Prague, Publication House Czechoslovak Acad.Sci. 515-526.

Endo, M., 1977 "Calcium release from sarcoplasmic reticulum". Physiol.Rev. 57: 71-108.

Fernstrom, J. D. and Fernstrom, M. H., 1984 "Effects of caffeine on monoamine neurotransmitters in the central and peripheral nervous system". In: Caffeine: Perspectives from Recent Research, Edited by P. B. Dews, Berlin, Springer-Verlag, 107-117.

Fredholm, B. B., 1985 "On the mechanism of action of theophylline and caffeine". Acta Med.Scand. 217: 149-153.

Lakomy, H. K. A., 1986 "Measurement of work and power output using friction-loaded cycle ergometers". Ergonomics 29: 509-517.

Lopes, J. M., Aubier, M., Jardin, J., Aranda, J. V. and Macklem, P. T., 1983 "Effect of caffeine on skeletal muscle function before and after fatigue". J.Appl.Physiol. 54: 1303-1305.

Macintosh, B. R., Barbee, R. W. and Stainsby, W. N., 1981 "Contractile response to caffeine of rested and fatigued skeletal muscle". Med.Sci.Sports Exer. 13: 95.

Rall, T. W., 1980 "Central nervous system stimulants". In: The Pharmacological Basis of Therapeutics, Edited by A. G. Gilman, L. S. Goodman, T. W. Rall and F. Murad, New York, MacMillian, 592-607.

Routh, J. I., Shane, N. A., Arredondo, E. G. and Paul, W. D., 1969 “Determination of caffeine in serum and urine". Clin.Chem. 15: 661-668.

Van Handle, P., 1983 "Caffeine". In: Ergogenic Aids in Sport, Edited by M. H. Williams, Champaign, Human Kinetics Publishers, 163-182.

Varagic, V. M. and Zugic, M., 1971 "Interactions of xanthine derivatives, catacholamines and glucose-6-phosphate on the isolated phrenic nerve diaphragm preparation of the rat". Pharmacology 5: 275-286.

Waldek, B., 1973 "Sensitization by caffeine of central catacholamine receptors". J.Neural.Trans. 34: 61-72.

Williams, J. H., Barnes, W. S. and Gadberry, W. L., 1987 "Influence of caffeine on force and EMG in rested and fatigued muscle". Am.J.Phys.Med. 66: In Press.

Wilson, D. F., 1973 "Effects of caffeine on neuromuscular transmission in the rat". J.Appl.Physiol. 255: 862-865.

Yamaguchi, T., 1975 "Caffeine induced potentiation of twitches in frog single muscle fibers". Jpn.J.Physiol. 25: 695-704.

Title: $\quad$ THE NEW CASE FOR EXERCISE

Authors: $\quad$ P. H. Fentem, E. J. Bassey and N. B. Turnbull

Publishers (joint): The Sports Council and the Health Education Authority, London, 1988

Price: £2.95 40 pages No Index No figures 241 references Paper cover ISBN 09036525522

To the readers of this journal, the booklet putting the case for exercise is preaching to the converted. The benefits of exercise are described in easily-understood terms for growth and development in the young, for helping the asthmatic and diabetic child, and for the middle-aged men the cardiovascular effects already described so well in extensive investigations on bus crews and civil servants by Jerry Morris and many others. Inactive athletes are at the same risk as inactive men of the same age, so the lesson is to keep up exercise, even of a different type from the athlete's heyday. The value of exercise following myocardial infarction is described, but strangely there is no mention, either to support or to condemn, the vigorous postinfarction programmes of Canadian authors such as Roy Shephard or his co-workers, Banniser and Kavanagh. Moderate exercise in pregnancy is advocated, but the risk of a week's prematurity and a light-weight baby after extremely heavy exercise programmes are mentioned. No adverse effect has been found in the literature of carefully prescribed exercise in the elderly or the obese. Most cardiac incidents occur as a result of pre-existing disease, ignoring warning symptoms (and doctors are particularly bad examples of this!), or engaging in unfamiliar, stressful exercise without prior training.

The most valuable part of this booklet is the reference section, with 241 references listed, mainly from American journals, and many of the authors being the Scandinavian authorities so well known to us in the UK. The book would appear to be written essentially for doctors and other health professionals, as some terms such as "CHD" and " $\mathrm{VO}_{2}$ ", without definition, would not be understood by many laymen. A valuable reference to show to patients, and to provide an unequalled bibliography on the benefits of exercise.

Henry E. Robson 